\title{
Prevalence and Associated Risk Factors of Bronchial Asthma in Children in Santo Domingo, Dominican Republic
}

Stephanie G. Mejias ${ }^{1}$, Kamleshun Ramphul ${ }^{2}$

1. Pediatrics, The University Iberoamericana Unibe School of Medicine/Robert Reid Cabral Children's Hospital, Santo Domingo, DOM 2. Pediatrics, Shanghai Jiao Tong University School of Medicine/Shanghai Xin Hua Hospital, Shanghai, CHN

$\square$ Corresponding author: Kamleshun Ramphul, adramphul@hotmail.com Disclosures can be found in Additional Information at the end of the article

\section{Abstract}

\section{Background}

Bronchial asthma is an important health problem worldwide. There is insufficient data on the prevalence of bronchial asthma among school children in Santo Domingo, Dominican Republic.

\section{Objective}

The objective of this study is to assess the prevalence of asthma and its related risk factors among school children in Santo Domingo, Dominican Republic.

\section{Materials and methods}

A cross-sectional study using a modified questionnaire was conducted in Santo Domingo among 600 children aged three to 11 eleven years. The prevalence of asthma and its associated risk factors such as birth order, family history of asthma, family history of allergy, exposure to pets at home, exposure to tobacco smoke, and source of fuel used at home were collected. The relevant data collected was analyzed using the Statistical Package for the Social Sciences (SPSS) 24.0. (IBM Corp., Armonk, NY) software.

\section{Results}

The prevalence of asthma was found to be $22.0 \%$. Age, family history of asthma, family history of allergy, exposure to tobacco smoke, and birth order showed statistical significance. The source of fuel used at home, gender, and exposure to pets were not statistically significant to be considered as risk factors associated with asthma in the population studied.

Received 02/08/2018

Review began 02/15/2018 Review ended 02/16/2018 Published 02/20/2018

\section{(c) Copyright 2018}

Mejias et al. This is an open access article distributed under the terms of the Creative Commons Attribution License CC-BY 3.0., which permits unrestricted use, distribution, and reproduction in any medium, provided the original author and source are credited.

\section{Conclusion}

With an asthma prevalence of $22.0 \%$ in the pediatric population, the Dominican Republic has one of the highest national rates of asthma in the pediatric population in Latin America. Proper education, screening, and prevention can help lower the burden of this disease economically and socially.

Categories: Pediatrics, Allergy/Immunology, Pulmonology

Keywords: asthma, pediatrics, santo domingo 


\section{Introduction}

Asthma is a chronic respiratory disorder involving the airways and is characterized by variable and recurring symptoms. It is usually associated with airflow obstruction, inflammation, and bronchial hyper-responsiveness [1]. Asthma is one of the most important chronic diseases worldwide and it affects individuals of all ages [2]. Patients usually present with occasional episodes of asthma attacks, breathlessness, wheezing, and chest tightness [3]. The allergen or precipitating factor causes airway hyper-responsiveness that leads to narrowing of the passages, causing obstruction of airflow [4].

There is a huge variation in the incidence rate of asthma geographically. In African countries the incidence ranges from $18 \%$ in Kenya to $20 \%$ in South Africa [5], while in the Asian continent, Pakistan [6] has an incidence rate of $15.8 \%$ and India, 5.3\%. Recent studies have shown that in most of the Latin America countries, the prevalence of asthma varied from $2.6 \%$ in Guatemala [7] to 33.1\% in Peru [8]. In 2012 Caban-Martinez et al. found that the overall prevalence of asthma in the general population of the Dominican Republic was 14.2\% [9], and in 2017 Sun et al. noted a prevalence rate of $25.7 \%$ [10] in the pediatric population, though the sample size in the latter research was only 74 participants recruited at a medical outreach clinic in Santo Domingo, Dominican Republic.

Asthma is one of the most prevalent chronic conditions in the Dominican Republic and its impact and burden on society and children's development continues to rise [11]. The aim of this study is to evaluate the prevalence of childhood asthma and its associated risk factors over a larger sample size in Santo Domingo, Dominican Republic. This will provide a more reliable baseline data on the prevalence of asthma in the pediatric population in the Dominican Republic, which in turn can help improve policies, screening protocols, and guidelines for asthma detection and control.

\section{Materials And Methods}

A descriptive cross-sectional study was conducted involving 624 randomly selected children in Santo Domingo, Dominican Republic from October 2017 to December 2017. The sample was evenly divided into males and females and then further divided into four age groups ranging from three to 11 years of age. Six hundred forms that were properly filled and returned were considered for our study, giving a response rate of $96.2 \%$.

Prior permission was obtained from the Dean of the school to allow students to participate. Teachers were given a quick orientation of how to help in the data collection. A questionnaire based on the International Study on Allergy and Asthma [12] was set up and some modifications were made to meet the requirements of the study. The questionnaires were filled in by the parents, and any questions they had were answered by phone and a contact number was listed on each form. The questionnaire was written in both English and Spanish.

Diagnosis of asthma in the children was made according to the guidelines of the American Thoracic Society for the diagnosis of asthma [13]. The first part of the questionnaire focused on the presence and prevalence of wheezing in the children and other atopic conditions such as rhinitis and rashes and their frequency over the last 12 months. The second part consisted of the major risk factors, which included exposure to tobacco smoke at home, presence of any pets, family history of asthma, family history of allergy, type of fuel source used at home, and the birth order.

The collected data was entered into a Microsoft Excel spreadsheet and analyzed using the Statistical Package for the Social Sciences (SPSS) version 24.0. (IBM Corp., Armonk, NY) software package for Windows. Chi square test was used to analyze for associations between 
categorical variables. Statistical significance was set at $\mathrm{p}<0.05$.

Ethical clearance was obtained from the school boards, written consent was obtained from the parents of the children, and assent was obtained from the children. Privacy and confidentiality of all participants were maintained.

\section{Results}

Six hundred students were considered for the study, of which 300 were males (50\%) and 300 females (50\%). In this study, 132 participants were diagnosed with asthma and the prevalence was calculated as $22.0 \%$. Fifty-nine males (19.7\%) and 73 females (24.3\%) were diagnosed with asthma. No statistical significance was found between gender and the prevalence of asthma in our study. Fourteen children aged between three and five years (9.3\%), 33 aged between five and seven years (22.0\%), 43 aged between seven and nine years (28.6\%), and 42 children between nine and eleven years (28.0\%) were diagnosed with asthma in Santo Domingo and this was statistically significant $(\mathrm{p}<0.05)$.

Among the 132 children diagnosed with asthma, 30 had a family history of asthma and 43 had a family history of allergy and these two findings were both statistically significant $(\mathrm{p}<0.05)$. Sixty children diagnosed with the disease had also been exposed to tobacco smoke while 72 children with asthma were not exposed and this showed statistical significance $(\mathrm{p}<0.05)$. Fortytwo of the 132 children were first-born children, 68 were second-born, and 22 were the third or higher child in the family. A statistical significance was found $(\mathrm{p}<0.05)$ between the birth order and the prevalence of asthma.

In this study we found out that 48 of the asthmatics also had at least one pet at home but no statistical significance was found. Forty-four children with asthma were exposed to gas as a fuel source at home in the kitchen while 88 had an electric source in the kitchen for cooking. No statistical significance was noted in both cases.

The frequencies of the symptoms seen in the asthmatics are shown in Table 1 and the risk factors in Table 2. In this study 98 children (74.2\%) had one to three episodes of wheezing over the last 12 months and 34 (25.8\%) had more than three. We found that 103 children (78.0\%) also suffered from rhinitis and 93 (70.5\%) were diagnosed with atopic rashes over the last year. 


\section{Cureus}

\section{Condition}

Wheezing Episode

One to three episodes

Four or more episodes

Rhinitis

Present

Absent

Rashes

Present

Absent

\section{Prevalence}

$98(74.2 \%)$

$34(25.8 \%)$

$103(78.0 \%)$

$29(22.0 \%)$

$93(70.5 \%)$

$39(29.5 \%)$

TABLE 1: Presentation of symptoms in the asthmatics over the last 12 months.

\section{Associated factor}

Sex

Male

Female

Age

Three to five

Five to seven

Seven to nine

Nine to eleven

Birth order

First child

Second child

Third child or more

Source of fuel used at home

Gas

Electric

Family history of asthma
Asthma ( $n=132)$

Non-asthma $(n=468)$

$P$ value

59

241

227

136

33

117

107

108

42

95

68

320

0.01612

22

53

44

200

88

268 


\section{Cureus}

Present 30

Absent

Family history of allergy

Present

43

69

Absent

89

400

Pets at home

Yes

48

84

60

72

28

440

$<0.01$

02

(1)

No

Exposure to tobacco smoke at home

Yes
133

295

TABLE 2: Associated factors and the risk of asthma in children from Santo Domingo, Dominican Republic.

\section{Discussion}

The prevalence of asthma in our study for the pediatric population in Santo Domingo, Dominican Republic was $22.0 \%$. It is different from the study conducted by Sun et al. in 2017 for the same population. The sample size, 600 children in our study and 74 children in their study, and the place where the volunteers were recruited, i.e. a school for our study and a clinic for their study, are the possible reasons for the discrepancy noted in the results. The prevalence of $22.0 \%$ in the pediatric population is higher than that in the general population (14.2\%, CabanMartinez et al., 2012). However, the finding of $22.0 \%$ is very similar to the range in the pediatric population of many Latin American countries such as Honduras (18.3\%), Panama (20.5\%), Costa Rica (23.2\%), and Cuba (30.9\%). The environmental exposure and the genetic predisposition in such regions can be some of the major factors for the higher prevalence rate compared to populations of different ethnic backgrounds. In India, for the same ethnic population, the prevalence varied from $7.59 \%$ in a less polluted region [14] to $19.34 \%$ in a heavy traffic region [15].

Statistical significance was found between birth order and the prevalence of asthma. IL13 gene polymorphism on serum IgE has been associated with birth order [16] and this can be one of the major reasons for the difference observed in our study. Family history of asthma and allergies showed statistical significance in our study. Asthma is a multifactorial condition and recent advances in molecular biology and genetics have strongly suggested that it can be a hereditary disorder based on several factors, including genes [17, 18]. Multiple genetic predispositions have been found in Hispanic populations including the role of PDE4D and PDE4 inhibitors, upon which medications have even been developed for asthma [19].

The presence of at least one smoker in the family showed statistical significance in our study. Passive smoking can be a major risk factor to hyper-responsiveness of airways. Exposure to environmental tobacco smoke (ETS) can lead to poor asthma control in children causing 
frequent exacerbations and hospitalizations [20-23]. Various studies have shown that exposure of children to tobacco smoke can predispose them to a higher incidence of other pulmonary symptoms (wheezing, asthma, cough, pneumonia, impaired pulmonary function, chronic bronchitis) [24-26] as well as adenoid hypertrophy [27], tonsillitis, and sore throats [28]. Liem et al. showed that parents with a child diagnosed with asthma were unlikely to quit smoking or smoke outside [29]. However, a proper education of the risk factors associated with second hand smoking and asthma and the benefits of protecting their asthmatic children from tobacco exposure should be done in Santo Domingo as the ethnic background of their study and the population in the Dominican Republic is different and the results may vary.

One major limitation of this study is the fact that the prevalence of asthma in one specific geographic region, i.e. Santo Domingo, cannot be interpreted as the prevalence of asthma in the Dominican Republic. Consequently, multiple studies across different rural and urban regions should be performed to improve the accuracy of the prevalence noted.

\section{Conclusions}

The study found that approximately $22.0 \%$ of children aged three to 11 years in Santo Domingo suffered from asthma. Age, birth order, family history of asthma and allergy, and exposure to tobacco smoke at home were all associated with the prevalence of asthma. No relationship was found between genders, source of fuel used at home, exposure to a pet and the prevalence of asthma. The higher prevalence of $22.0 \%$ corresponded to the same range noted in different studies carried out across different Latin American countries.

\section{Additional Information Disclosures}

Human subjects: Consent was obtained by all participants in this study. Animal subjects: All authors have confirmed that this study did not involve animal subjects or tissue. Conflicts of interest: In compliance with the ICMJE uniform disclosure form, all authors declare the following: Payment/services info: All authors have declared that no financial support was received from any organization for the submitted work. Financial relationships: All authors have declared that they have no financial relationships at present or within the previous three years with any organizations that might have an interest in the submitted work. Other relationships: All authors have declared that there are no other relationships or activities that could appear to have influenced the submitted work.

\section{References}

1. Walter H, Sadeque-Iqbal F, Ulysse R, Castillo D, Fitzpatrick A, Singleton J: The effectiveness of school-based family asthma educational programs on the quality of life and number of asthma exacerbations of children aged five to 18 years diagnosed with asthma: a systematic review protocol. JBI Database System Rev Implement Rep. 2015, 13:69-81. 10.11124/jbisrir2015-2335

2. The Global Asthma Report 2014 . (2014). Accessed: February 14, 2018: http://www.globalasthmareport.org/burden/burden.php.

3. Pokharel PK, Pokharel P, Bhatta NK, Pandey RM, Erkki K: Asthma symptomatics school children of Sonapur. Kathmandu Univ Med J (KUMJ). 2007, 5:484-487.

4. Eder W, Ege MJ, von Mutius E: The asthma epidemic. N Engl J Med. 2006, 355:2226-2235. 10.1056/NEJMra054308

5. Ait-Khaled N, Odhiambo J, Pearce N, et al.: Prevalence of symptoms of asthma, rhinitis and eczema in 13- to 14-year-old children in Africa: the International Study of Asthma and Allergies in Childhood Phase III. Allergy. 2007, 62:247-258. 10.1111/j.13989995.2007.01325.x

6. Hasnain SM, Khan M, Saleem A, Waqar MA: Prevalence of asthma and allergic rhinitis among 
school children of Karachi, Pakistan, 2007. J Asthma. 2009, 46:86-90.

10.1080/02770900802513023

7. Schei MA, Hessen JO, Smith KR, Bruce N, McCracken J, Lopez V: Childhood asthma and indoor woodsmoke from cooking in Guatemala. J Expo Anal Environ Epidemiol. 2004, 14:110117. 10.1038/sj.jea.7500365

8. Checkley W, Robinson CL, Baumann LM, et al.: 25-hydroxy vitamin D levels are associated with childhood asthma in a population-based study in Peru. Clin Exp Allergy. 2015, 45:273282. 10.1111/cea.12311

9. Caban-Martinez AJ, Halder GE, Tellechea L, et al.: Health status and behaviors among adults residing in rural Dominican Republic. Rural Remote Health. 2012, 12:1956.

10. Sun WW, Gupta L, Andreae AE, et al.: Prevalence of pediatric asthma risk in Santo Domingo, Dominican Republic. Ann Glob Health. 2017, 83:293-299. 10.1016/j.aogh.2016.12.002

11. Busi LE, Sly PD, Restuccia S, Llancaman L: Validation of a school-based written questionnaire for asthma case identification in Argentina. Pediatr Pulmonol. 2012, 47:1-7.

10.1002/ppul.21500

12. Asher MI, Keil U, Anderson HR, et al.: International Study of Asthma and Allergies in Childhood (ISAAC): rationale and methods. Eur Respir J. 1995, 8:483-491.

13. Statement on standards for the diagnosis and care of patients with chronic obstructive pulmonary disease (COPD) and asthma. This official statement of the American Thoracic Society was adopted by the ATS Board of Directors, November 1986. Am Rev Respir Dis. 1987, 136:225-244. 10.1164/ajrccm/136.1.225

14. Sharma BS, Kumar MG, Chandel R: Prevalence of asthma in urban school children in Jaipur, Rajasthan. Indian Pediatr. 2012, 49:835-836.

15. Paramesh H: Epidemiology of asthma in India. Indian J Pediatr. 2002, 69:309-312.

16. Ogbuanu IU, Karmaus WJ, Zhang H, Sabo-Attwood T, Ewart S, Roberts G, Arshad SH: Birth order modifies the effect of IL13 gene polymorphisms on serum IgE at age 10 and skin prick test at ages 4, 10 and 18: a prospective birth cohort study. Allergy Asthma Clin Immunol. 2010, 6:6. 10.1186/1710-1492-6-6

17. Leung TF, Tang NL, Chan IH, Li AM, Ha G, Lam CW, Fok TF: Distribution in allele frequencies of predisposition-to-atopy genotypes in Chinese children. Pediatr Pulmonol. 2002, 34:419424. 10.1002/ppul.10210

18. Leung TF, Chan IH, Wong GW, Li CY, Tang NL, Yung E, Lam CW: Association between candidate genes and lung function growth in Chinese asthmatic children. Clin Exp Allergy. 2007, 37:1480-1486. 10.1111/j.1365-2222.2007.02799.x

19. Himes BE, Hunninghake GM, Baurley JW, et al.: Genome-wide association analysis identifies PDE4D as an asthma-susceptibility gene. Am J Hum Genet. 2009, 84:581-593.

10.1016/j.ajhg.2009.04.006

20. Abulhosn RS, Morray BH, Llewellyn CE, Redding GJ: Passive smoke exposure impairs recovery after hospitalization for acute asthma. Arch Pediatr Adolesc Med. 1997, 151:135-139. 10.1001/archpedi.1997.02170390025005

21. Cook DG, Strachan DP: Summary of effects of parental smoking on the respiratory health of children and implications for research. Thorax. 1999, 54:357-366.

22. Cook DG, Strachan DP: Health effects of passive smoking. 3. Parental smoking and prevalence of respiratory symptoms and asthma in school age children. Thorax. 1997, 52:1081-1094.

23. Wakefield M, Banham D, Martin J, Ruffin R, McCaul K, Badcock N: Restrictions on smoking at home and urinary cotinine levels among children with asthma. Am J Prev Med. 2000, 19:188192.

24. DiFranza JR, Aligne CA, Weitzman M: Prenatal and postnatal environmental tobacco smoke exposure and children's health. Pediatrics. 2004, 113:1007-1015.

25. Li JS, Peat JK, Xuan W, Berry G: Meta-analysis on the association between environmental tobacco smoke (ETS) exposure and the prevalence of lower respiratory tract infection in early childhood. Pediatr Pulmonol. 1999, 27:5-13. 10.1002/(SICI)1099-0496(199901)27:1<5::AIDPPUL3>3.0.CO;2-5

26. Colley JR, Holland WW, Corkhill RT: Influence of passive smoking and parental phlegm on pneumonia and bronchitis in early childhood. Lancet. 1974, 2:1031-1034.

27. Huang SW, Giannoni C: The risk of adenoid hypertrophy in children with allergic rhinitis . Ann Allergy Asthma Immunol. 2001, 87:350-355. 10.1016/s1081-1206(10)62251-x

28. Willatt DJ: Children's sore throats related to parental smoking . Clin Otolaryngol Allied Sci. 


\section{Cureus}

1986, 11:317-321. 10.1111/j.1365-2273.1986.tb02018.x

29. Liem JJ, Kozyrskyj AL, Benoit CM, Becker AB: Asthma is not enough: continuation of smoking among parents with an asthmatic child. Can Respir J. 2007, 14:349-353. 